\title{
ON THE PARALYSIS WHICH RESULTS FROM ANGULAR CURVATURE OF THE SPINE.
}

BI JOHN DUNCAN, M.D.,

Surgeon to the Edinburgh Royal Infirmary, Lechurer on Surgery.

Cases of caries may be divided into two classes, of which the types are very distinct, although they shade into one another with an infinite gradation. In the one class are those in which the disease has a constitutional, in the other those in which it has an external etiology.

In the spine it appears to me that this distinction is as distinctly marked as in other parts of the body. Patients of the first group have the strumous or tubercular diathesis; near relations have had phthisis, or white swelling, or glandular inflammations. They have themselves the general characters of the diathesis, or have suffered from its pathological manifestations. They have spat blood or had pleurisy. They have scars in the neck, or tabercle in the lungs, or chronic joint-disease. In short, the personal or family history is bad.

In such cases the angular curvature is rapid in its formation. Psoas, or lumbar, or cervical abscesses form early in the disease. The patients sink from hectic or from amyloid degeneration of the liver and kidney. If paralysis make its appearance it is commonly from pressure on the cord, and is sometimes suddenly fatal in the cervical region.

Patients in the second class have generally some distinct history of serious injury. Their appearance is robust and healthy. The family and personal history is free from trace of strumous disease. Abscess is comparatively a rare occur- 
rence. Paralysis, on the contrary, appears soon. Sometimes it precedes the projection of the spines, and is accompanied only by tenderness on pressure or percussion, or on the application of heat or cold. The patients die from the effects of the paralysis, and if there be no paralysis the disease runs an exceedingly slow course. While the strumous form attacks the child or the young adult, this variety is more common in middle or advanced life.

The paralysis is peculiar. It confines itself specially to the motor track of the cord. Sensation is rarely affected. The motor paralysis is often of the spastic form, and is sometimes very extreme. The lower limbs are most apt to become paralysed. The bladder and bowels retain their normal functions, or are only temporarily disturbed. Trophic changes also are infrequent.

I have been much struck by the distinct way in which all these peculiarities come out in the series of cases which I shortly append. They are those which have been resident in the wards under my care during the last two years, having been admitted for the purpose of opening the abscess or for observation. Many other cases of the strumous variety were out-patients during the same period, but I have not met with any other examples of paralysis.

I.-Jessie S., æt. 31, married, admitted 18th December, 1878. Sallow and thin. Her mother died of phthisis, and her father died young. She is very subject to indigestion. About 4 years ago she felt pain in the back after delivery of her second child. She was unable to carry it about, and has not been free from the pain since that time. Three months ago swelling appeared about Poupart's ligament, which was opened. There is prominence of the 11th and 12th dorsal vertebræ. A plaister jacket was applied. In June, 187.9, the discharge, though slight, still continued, and there was little alteration in the general condition.

II.-Harriet M., æt. 23, single, admitted 19th June, 1878.

History. Family: Mother and two sisters died of phthisıs. A brother had an abscess in his side, which has now healed.

Personal: Amputation of the third toe of the left font was 
performed a year ago, on account of caries. There is now caries of the metacarpo-phalangeal joint of the left thumb.

There is lumbar abscess, and projection, and pain on pressure over the 4th and 5th dorsal vertebræ.

The abscess was aspirated and a jacket applied. When last heard of, the patient was progressing favourably.

It would be tedious to enter into the history of common cases of which these may be taken as the types. In all the treatment was either aspiration or antiseptic opening of the abscess, with the use of the plaister jacket. I enumerate only and mention the salient points.

III.-Duncan C., æt. 22. Psoas abscess and angular projection of the 10th and 11th dorsal vertebræ. Has twice had inflammation of the lungs, and the present signs of phthisis are distinct. A brother had white swelling of the knee.

IV.-John L., æt. 23, admitted 7th November, 1879. Psoas abscess and angular curvature of $6 \mathrm{th}, 7 \mathrm{th}$, and 8th dorsal vertebræ. He refers his disease to a fall downstairs, but it is clearly ascertained that the projection existed before the fall, although the pain was thereby increased. Some years ago he had abscesses in the right arm, which lasted several monthy. His mother died after child-birth.

V.-A. D., æt. 3, admitted January, 1880. Double psoas abscess and excessive curvature in lower dorsal region. Two cases of phthisis in the family. The treatment is by double extension.

VI.-Patrick D., æt. 31. Pale, thin, and strumous-looking. Lumbar abscess and angular curvature of 7 th dorsal spine. Knows nothing of family history. No injury or previous illness.

VII.-William S., æt. 25. Lumbar abscess and projection of 7 th and 8th dorsal vertebræ. No history of injury. A brother has scars in his neck.

VIII.-John N., æt. 15. Caries of 3rd and 4th cervical vertebræ. Father died of phthisis. In this case I opened a retro-pharyngeal abscess by the method adrocated by $\mathrm{Mr}$. Hilton and Mr. Chiene. Unfortunately it opened also into the pharynx a week afterwards, and consequently became septic. He comes in to show himself occasionally, and is 
getting much emaciated from the discharge, which has now been going on for more than a year. He has also had several fits. The epilepsy, however, I believe to be connected with carie-necrosis of the right temporal bone in the mastoid region. which is considerable in extent.

In none of these cases was there the slightest paralytic symptom.

The following cases illustrate the other form of disease of the vertebral bodies to which I have referred.

I.-The first case which attracted my notice was that of a miner, xt. 23, whom Professor Saunders asked me to see in his ward. There was marked angular curvature of the lowest cervical and upper dorsal vertebræ, with an unusual amount of inclination to the left. He said he had been in the habit of carrying exceedingly heavy weights on the left shoulder, and on several occasions was conscious of having strained the parts. In fact, he felt assured that he had immediately produced the lump in one of his "lifts." There was considerable pain on pressure. $\mathrm{He}$ had spastic paralysis of the lower extremity to an extreme degree. The tendon reflex was enormously exaggerated, and he was unable to walk more than a few paces, even with assistance, on account of the spasmodic jerking of his limbs. I applied the plaister jacket, with jury-mast and elastic support for the head. He at once began to improve. He still after a year continues to wear the apparatus, and sends me word that he can go about as well as ever, but his legs, he thinks, " make him walk faster than he would otherwise do."

II.-John K., æt. 27. Admitted December 7th, 1878. Family and personal history good.

A year before admission he fell from a ladder while carrying a heavy load of lead. He injured his back, and thereafter wore a belt for two months before he observed the projection of his spine. The 5th, 6th, and 7 th dorsal vertebræ are prominent. He has distinct loss of power in the legs, which he moves in a jerking manner. The patellar tendon reflex is increased. Sensation is normal. He had a plaister of Paris jacket applied. The pain and paralysis much improved when he was last heard of, six months after leaving. He then showed, himself for renewal of the jacket. 
III.-John D., miner, æt. 53. Admitted May 6th, 1879. The family and personal history are unexceptionable. $\mathrm{He}$ is not aware of any special injury, but says that he has often felt his occupation a strain on his back.

He has felt pain in his back for about a year, and noticed the projection of the 4th dorsal spine several months ago. For three or four weeks his legs have been getting weaker. $\mathrm{He}$ is now barely able to walk with assistance, and his legs hwve a great tendency to cross in doing so. The tendon reflex is much. increased in every action. Sensation is slightly duller than normal in the lower limbs. The bowels are sluggish. A jacket was applied, but fitted badly, and during the ten days he was in the infirmary he rapidly deteriorated. At the end of that time he was, quite unable to stand alone. A better jacket was adjusted, and he at once began to improve. He returned January, 1880, to ask whether he might resume light work. He could then walk without the least apparent impediment.

IV.-Henry B., æt: 13. The family history is good. There is no history of injury. The 3rd, 4th, and 5th dorsal spines project. The disease has been in progress for three years, but there is no sign of abscess. On the other hand, the spastic paralysis is so marked that he cannot walk even with assistance. $\mathrm{He}$ has had a jacket on now several months, but although the locel pain is relieved the paralysis is steadily getting worse.

V.-Thomas B., miner, æt. 32. Admitted 6th Feb. 1880, a robust-looking man; family history perfectly good.

As a boy he pushed waggons in the mine by laying his head against them, and remembers straining his neck when he was seventeen so severely that the pain lasted for a year, during which he could not work. Since then the neck has been stiff. Six years ago he lost the power of his fingers, and shortly afterwards of his legs. The fingers-are now nearly well. The legs have got gradually worse, and he is now quito unable to walk. He has on several occasions had difficulty in passing water. This was much relieved by. the application of a blister to the nape of the neck. The actual cautery his been 'nsed three times, twice with' decided but temporary 
inprovement in the paralysis. Sensation is not affected; he can move his limbs pretty freely in bed, but cannot support himself. Tendon reflex is increased. The neck is shortened, and quite stiff. There is no abscess. The plaister jacket was upplied 9th Feb. 1880.

VI.-William B., miner, æt. 38. Admitted July, 1879. Family history good. No previous illness. He once broke his thigh, and has had several severe injuries to the back, but cannot attribute his present illness to any one in particular. He has had pain in the back for two years, but left off work only five weeks ago, when the doctor observed the prominence of the 4th dorsal spine. The patient walks with great difficulty, and has all the symptoms of spastic paralysis. The leg continues to twitch for a considerable time after the stroke on the tendon. A plaister jacket was applied, when he immediately began to improve. It was renewed in Jan. 1880, when the paralysis was found to have almost disappeared.

VII.-James McGlore, wt. 37, miner. Patient of Dr. Muirhead's. The family history is unexceptionable. Four years ago, just before his illness commenced, he slept out all night while intoxicated. For two years he had paralysis and pain in the back, but no projection. The 3rd dorsal spine is now prominent. The legs are constantly and rigidly contracted, flexed, and crossed. If the great toe be forcibly flexed the $\operatorname{limb}$ is involuntarily straightened, but soon recovers its abnormal posture. Two years ago he had some difficulty in urination and defæcation, but it speedily passed off. Double extension was used, and the actual cautery applied, but without benefit.

VIII.-W. M., æet. 38. Admitted Feb. 1880. The family and personal history is good. He has met with no serious injury. Pain in the back came on about six months ago, with projection of 12th dorsal spine. $\mathrm{He}$ has distinct spastic paralysis with increased tendon reflex. There is no abscess. A plaister jacket has been applied.

The following cases differ from the others in several important features, and may be regarded as links in the chain which unites the two classes together :-

I.-James H., et. 42. Patient of Dr. Muirhead's. A brother VOL. IIJ. 
died of phthisis. The disease began four years ago, without known cause. Pain in and projection of the 3rd, 4th, and 5th dorsal spines were at once observed, and an abscess soon afterwards formed a little lower down, which still continues to discharge. In August, 1879, he began to feel loss of power in the limbs, and abdominal constriction. He has now a trailing gait. The muscles are flaccid, and without spasm. The reflex action is diminished. The patellar-tendon reflex is slightly increased, especially on the left side.

II.-Patrick L., æt. 38, labourer. Admitted July, 1879. Family history good. He met with a severe injury to the back by f falling from a ladder a year ago, and immediately aftérwards a gradually increasing projection of the 5th dorsal spine commenced, followed shortly by an abscess a little lower down. There is no paralysis. The abscess was opened antiseptically, and he is now progressing favourably.

These cases, I think, mark very clearly the distiuction I have drawn between the strumous form of the disease and that which has its most striking analogy in the chronic interstitial absorption of the neck of the thigh-bone, which in adults so often follows severe injury. It will be noted that in this latter variety, to which I specially wish to direct attention, there was in almost every case a distinct history of injury, or of such an occupation as throws great strain upon the vertebral column. In the strumous the disease may have. its startingpoint in an injury, but most often the history is an afterthought, or the projection is said to have come of itself. The other peculiarities of caries siccum, to which I have already' referred, are also remarkably illustrated by these cases Of all these features the most singular seems to me the frequency with which it is accompanied by paralysis. I have no doubt that my experience of these two years has been unusual. Dr. Saunders's patient, an Ayrshire miner, was so greatly benefited by treatment that the patients T. B. and J. D., also miners in the same district, were induced to come by the report of his case. Still it is plainly much more frequent in this than in the strumous caries.

It will be noted that the paralysis was almost exclusively motor. It is a feature of all spinal disease that special tracts 
of the cord should be very accurately marked out by it. Whatever the explanation, it appears to characterise this consecutive paralysis as distinctly as the idiopathic. One can, to a certain extent, understand how the motor portions of the cord are most prone to become inflamed in consequence of caries of the bone. But it is more difficult to determine why the spastic form of paralysis should so greatly preponderate. In Dr. Saunders and Dr. Muirhead's patients the disease was severe and typical ; in others it was unmistakable, though not so far advanced. The cases are clear examples of those secondary degenerations which Türck and Charcot have doscribed.

The success of the treatment has been gratifying. Five cases have been sufficiently long under treatment to allow of a judgment being formed. Three of these have been practically cured, although they still wear the apparatus. In one case no benefit has resulted from the jacket. In another the jacket was not applied as it had previously been tried in Glasgow. For him I used the actual cautery without effect, and permanent extension in bed from head and feet, was applied, but not persisted in from the annoyance and inconvenience it occasioned.

It is plain that in this chronic ostitis, as in the same disease in other parts of the body, our local treatment is twofold, rest and counter-irritation. These cases illustrate the advantage that may be gained from both. The miner, Thomas B., was benefited on many occasions by blisters, and twice by actual cautery. Unfortunately the relief was not permanent. I fear that if counter-irritation be used alone this is the usual result, whether blisters, seton, or cautery be the means employed. 'To do much' good they require persistence, and with persistence comes a time when their beneficial effect ceases. They must be combined with rest. Now rest for the spinal column is difficult to procure. It implies abrogation both of motion and of pressure. 'This may be attempted in two ways; by retention in bed, or by the use of apparatus. Until Mr. Sayre made known the value of the plaister jacket, the inefficiency of apparatus was such that recumbency was the recognised treatment for disease of the spinal column, at least in the 
Edinburgh school. But if the objects aimed at by apparatus be attaiued, its other advantages are manifest: and I believe that they are in great measure so attained by the jacket. It does not take off perpendicular pressure so completely as recumbency does. If the jacket alone be used, the body telescopes gradually into it, and the plaister sinks en masse unless it be very accurately adjusted to the pelvis. If the disease be at or above the 6th dorsal vertebra, it is essential that the jury-mast be also applied, and the head attached to it by elastic bands which act much better than rigid straps. But while apparatus may not thoroughly relieve pressure, at least it very effectively restrains motion, which mere recumbency cannot. Even the actions of breathing are diverted from the ribs.

It is not essential that the material be plaister of Paris. That is usually most convenient. But I have moulded very comfortable jackets from the poroplastic splint material, and paraffin is light and easily applied in children, though not so durable and rigid in the adult.

The conclusions to be drawn from these cases are:

1st. That there are two distinct varieties of inflammation which attack the bodies of the vertebræ.

2nd. That in strumous cases there is comparatively little tendency to affection of the spinal cord.

3rd. That in chronic interstitial absorption there is a great tendency to paralysis, which presents the usual characters of what has been termed "pressure myelitis," with its secondary degenerations.

4th. That this paralysis may often be cured by rest and counter-irritation. 